\title{
Impact of Digital Convergence Technology on the Logistics Value Chain
}

\author{
Kui-hwa Park ${ }^{1}$ \\ ${ }^{1}$ Assistant Professor, Global Business Administration Department, Chungwoon University, \\ Incheon, Korea,khpark@chungwoon.ac.kr
}

\begin{abstract}
The purpose of this study is to analyze the impact of the introduction of digital convergence technology on the existing logistics value chain. Also, it intends to present future business directions for logistics companies in order to solve the difficulties in maintaining the sustainability and competitiveness of logistics companies with new technologies. To this end, three implications were presented by analyzing the impact on the logistics value chain, by conducting a theoretical arrangement through literature research and investigating cases where digital convergence technology was applied. First, digital convergence technology is most often applied to local delivery and transportation value chains, and other industrial companies (shippers) are leading rather than logistics companies. Second, the logistics management value chain, which is a unique task of logistics companies, is being replaced by platform companies. Third, the logistics value-added area is still less affected by digital convergence technology, and logistics companies need to maintain their competitiveness. In conclusion, a countermeasure for the introduction of digital convergence technology to secure customer experience of logistics companies, application of platform technology for horizontal cooperation, and construction of customized logistics service model in a cloud environment was presented. This study is based on an exploratory analysis of cases where digital convergence technologies were initially applied to the logistics value chains of industries (logistics companies and shippers), therefore, empirical analysis and continuous prediction of changes are needed in the future.
\end{abstract}

Keywords: Digital Convergency Technology, Logistics Value Chain, Fourth Industry Technology, Logistics Business Model, Logistics Technology

\section{Introduction}

Along with the fourth industrial revolution, new competitiveness and business models are emerging as robots, artificial intelligence, IoT, autonomous driving technology (vehicles), and drone technologies are applied to the logistics industry[1-6]. This change or direction of the logistics industry has led to a need for re-examination of the perception that it is more efficient for specialized logistics companies to perform the outsourced corporate logistics service just a few years ago. Online transportation platforms, such as Uber Freight, have emerged as new logistics competitors due to their cost-efficiency and ondemand response. Major shippers such as Amazon have begun offering their own logistics solutions. In addition, automakers that used to provide logistics transportation are armed with mobility services, threatening logistics companies. This change is due to the fact that the digital convergence technology, which can be called the fourth industrial revolution technology, has made it easier for companies other than logistics companies to enter the logistics value chain by newly changing the competitive factors of the existing logistics companies' unique value chains. In spite of the fact that digital convergence

Received: August 04, 2020; $1^{\text {st }}$ Review Result: September 21, 2020; $2^{\text {nd }}$ Review Result: November 04, 2020 Accepted: December 28, 2020 
technology has a significant influence on the change in the value chain of logistics companies, academic research in this field has been insufficient. Existing academic research has been conducted in the case of logistics technology application[1][2], the importance of technology introduction[7], and a general perspective on the digitalization of logistics[8], but rather, research from a practical perspective is attracting attention[9][10].

The purpose of this study is to investigate and review actual cases of industiries in order to analyze the impact on the existing logistics value chain with the introduction of digital convergence technology, and to present future business plans of existing logistics companies. To this end, in sections 2 and 3 , through literature research, digital convergence technology, logistics business model, and logistics value chain were summarized. In section 4, cases of digital convergence technology applied to logistics value chain were investigated and furthermore, implications were derived by analyzing the impact on the value chain of logistics companies. Based on the implications, in section 5, a plan to respond to changes in the value chain of future logistics companies is presented as a conclusion. This study was conducted based on exploratory analysis in the initial stage of application of digital convergence technology applied to the fourth industry revolution.

\section{Digital Convergence Technology and Logistics Business Model}

\subsection{Digital Convergence Technology}

Digital convergence technology is the technology that will lead the fourth industrial revolution at the World Economic Forum (WEF) in January 2016, and technologies that will affect future industries include mobile, cloud, big data, Internet of Things (IoT), robots, autonomous driving technology (vehicles), artificial intelligence (AI), bio technology, and 3D printing are presented[11]. In addition, Gartner publishes 10 Strategic Technology Trends every year. In 2020, the concept of "people-centered smart space"is hyperautomation, multiexperience, democratization, human augmentation, transparency, and traceability. The people-centered technology, empowered edge computing, distributed cloud, autonomous things, practical blockchain, and smart space technology of AI security were presented[12]. These technologies are applied to the entire business, creating a business model that provides new value through the convergence and application of technologies in each industry.

\subsection{Digital Convergence Technology and Logistics Business}

Digital convergence technology is also applied to the logistics sector, and a representative study is DHL's Logistics Trends Radar report. The DHL report published in 2016 presented predictive logistics, omnichannel logistics, on-demand delivery, big data, cloud logistics, IoT, robotics, and automation as technologies that will be activated within five years. Logistics marketplace, supergrid logistics, 3D printing, and autonomous driving technology (vehicles) were presented as logistics technologies to be used after five years[13]. In the DHL report published in 2018, AI, low-cost sensor technology, augmented reality, blockchain, next-generation wireless communication, and unmanned drones were added. The digital convergence technology of logistics and Supply Chain Management (SCM) was presented by WEF and Gartner, and various studies were conducted as the fourth industrial revolution technology[2][14]. Digital technology applied to the logistics is included in the Logistics Trend Radar (Version 2018/19) recently presented by DHL as shown in [Fig. 1][15].

DHL has been publishing reports on individual technologies and business models since 2013, and deals with big data, sensor technology, autonomous driving, drones, augmented reality, IoT, robotics, 3D printers, blockchain, AI, next-generation wireless communication, etc. in connection with logistics. Various researches on digital technology, logistics functions, and logistics business models were conducted, and business model types related to digital technologies of logistics startups were 
classified[3]. Logistics technologies related to the fourth industrial revolution were introduced and the effects of these technologies on the function of logistics were studied. The main technologies of the fourth industrial revolution related to supply chain management were introduced, and the research direction according to the trend of the supply chain management industry was analyzed through prior research[2]. A study on how logistics companies are receiving benefits from five new technology trends (Cloud Logistics, Supergrid Logistics, Anticipatory Logistics, Omni-Channel Logistics, and Additive Manufacturing (3D Printing)) was analyzed[4], and the fourth industrial logistics new technologies and the changing logistics industry were classified by type, and classified into a technology-led market expansion model, a technology-led efficiency optimization model, and a logistics innovation business model[5]. The ICT convergence technologies to innovate logistics services were presented by dividing into process automation, intelligent decision-making systems, and inter-company transaction platform technologies[6].

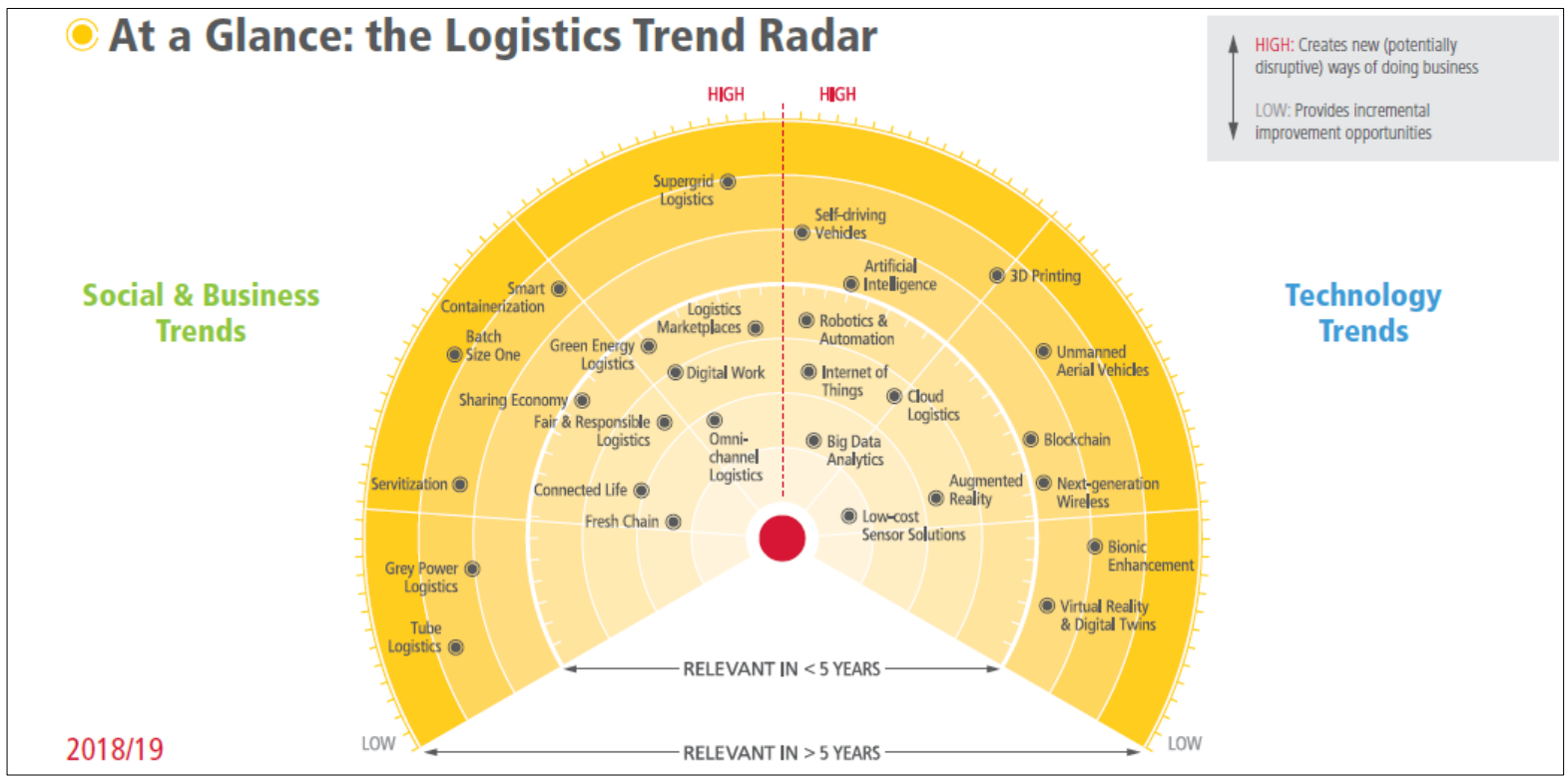

[Fig. 1] Logistics Trend Radar (Version 2018/19)

Digital convergence technology is applied by expanding its scope to the entire logistics function and supply chain management. The contents presented in previous studies and reports are summarized as shown in [Table 1].

[Table 1] Digital Convergency Technology and Applied Logistics Business

\begin{tabular}{|c|c|c|c|}
\hline $\begin{array}{c}\text { Digital Convergency } \\
\text { Technology }\end{array}$ & Logistics Business & How to apply & Related Research \\
\hline $\begin{array}{c}\text { Artificial Intelligence } \\
\text { (AI) }\end{array}$ & Transportation, inventory & Optimization technique & DHL (2018) [16] \\
\hline IoT & Transportation, warehouse & Sensor-based visibility & $\begin{array}{c}\text { Witkowski (2017) [1] } \\
\text { DHL (2015) [17] }\end{array}$ \\
\hline Robotics & $\begin{array}{c}\text { Warehouse, unloading, } \\
\text { packing }\end{array}$ & Labor productivity & $\begin{array}{c}\text { Lee Choong-bae et al. (2017) [2], Quartz (2016) } \\
\text { [18], wycha (2017) [19], DHL (2016) [20] }\end{array}$ \\
\hline Drones & $\begin{array}{c}\text { Transportation, Cold } \\
\text { Chain delivery }\end{array}$ & $\begin{array}{c}\text { New mode of transport } \\
\text { Lee Choong-bae et al. (2017) [2], DHL (2014) [21] }\end{array}$ \\
\hline Big data & $\begin{array}{c}\text { All fields of logistics } \\
\text { Capturing new business }\end{array}$ & Prediction technique & Witkowski (2017) [1], DHL (2013) [22] \\
\hline Cloud & Logistics information & sharing information & Schramm et al. (2011) [23] \\
\hline 3D printing & Transportation, inventory & Transport replacement & Lee Choong-bae et al. (2017) [2], DHL (2016) [24] \\
\hline
\end{tabular}




\begin{tabular}{|c|c|c|c|}
\hline $\begin{array}{c}\text { Autonomous driving } \\
\text { technology (vehicles) }\end{array}$ & Transportation & productivity & SyBaek (2017) [25], DHL (2014) [26] \\
\hline Augmented reality & $\begin{array}{c}\text { Logistics work (picking } \\
\text { equipment) }\end{array}$ & $\begin{array}{c}\text { Virtual reality technology } \\
\text { Digital twin }\end{array}$ & DHL (2014) [27] \\
\hline Blockchain & Logistics information & $\begin{array}{c}\text { Shared scalability } \\
\text { Security }\end{array}$ & $\begin{array}{c}\text { Seon Hwa, Kim Hyun Deok (2019) [28], DHL } \\
\text { (2018) [29] }\end{array}$ \\
\hline
\end{tabular}

\section{Logistics Service Provider Value Chain}

In general, Logistics Service Providers (LSP) are companies that provide logistics services. They are classified into various business groups such as transportation companies, express service companies, third-party logistics (3PL), and fourth-party logistics (4PL) according to the type of service provided [30][31]. It is difficult to describe a consistent scientific definition, but according to the existing literature, it is defined as 'a company that provides transportation and additional logistics services to other companies and individual customers'. In addition, based on the 3PL service type study[4] and the service range study[32], the business model that logistics companies provided value can be organized into four types [Fig.2]. Regional standard service providers provide basic logistics business (storage, forwarding, etc.), have a digital level of tracking and order processing, and have limited resources and capabilities to perform digital services. Niche specialized service providers operate small-scale businesses tailored to the specialized service needs of corporate customers and provide digital services suitable for specialized services. Global standard service providers provide multimodal services, cowork with local carriers, secure shipping and aviation space, perform some complex tasks, and provide cargo tracking, Electronic Data Interchange (EDI) services for customers, and transportation management solutions. Global specialized service providers provide customized services through customer-oriented global SCM management, and use complex digital solutions to manage global SCM.

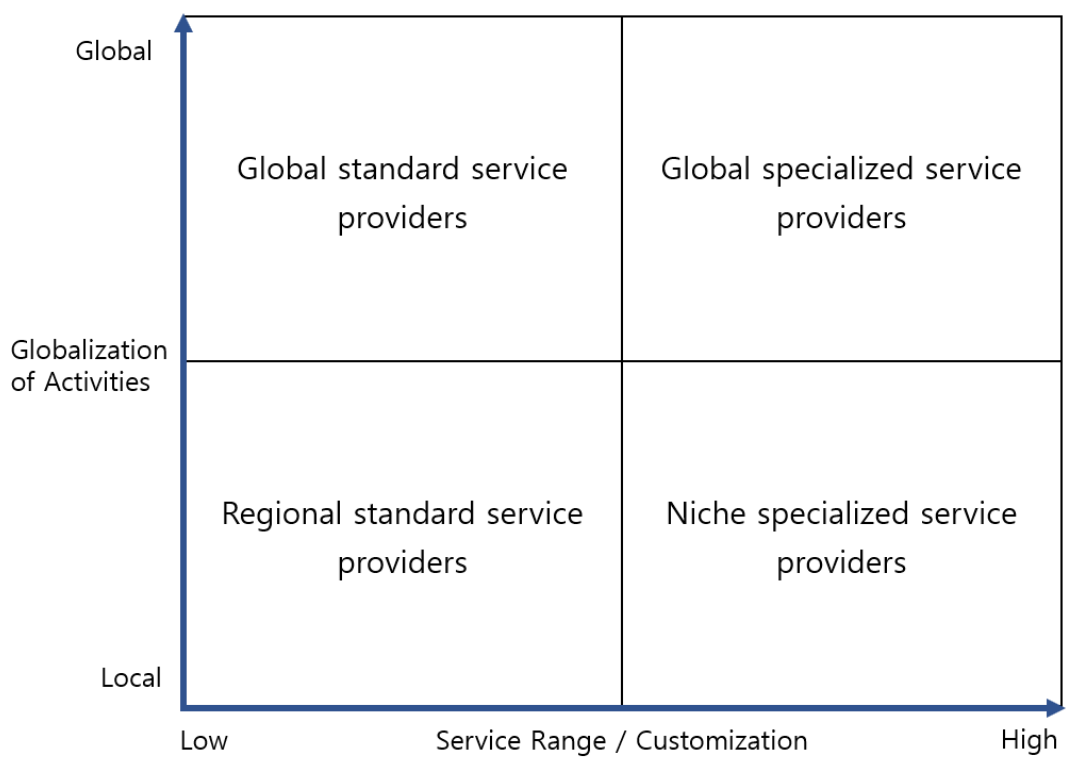

[Fig. 2] Third-Party Logistics (3PL) Business Models

Comparing the business model of the logistics company and the value chain stage, the logistics services that each business model focuses on and the detailed value chain of the logistics company can be summarized as major activities in [Table 2][33]. It can be seen that domestic and global standard service providers mainly focus on freight transport, while niche and global specialized service providers support the entire value chain and focus on value-added services. 
[Table 2] 3PL Business Models along the Logistics Service Value Chain and its Main Activities

\begin{tabular}{|c|c|c|c|c|c|}
\hline \multicolumn{4}{|c|}{ Business Models } & \multirow[b]{2}{*}{ Logistics Services } & \multirow[b]{2}{*}{ Main activities } \\
\hline $\begin{array}{c}\text { Regional } \\
\text { standard service } \\
\text { providers }\end{array}$ & $\begin{array}{c}\text { Global standard } \\
\text { service } \\
\text { providers }\end{array}$ & $\begin{array}{l}\text { Niche } \\
\text { specialized } \\
\text { service } \\
\text { providers }\end{array}$ & $\begin{array}{l}\text { Global } \\
\text { specialized } \\
\text { service } \\
\text { providers } \\
\end{array}$ & & \\
\hline \multirow{4}{*}{$\begin{array}{c}\text { Main } \\
\text { Activities }\end{array}$} & \multirow{4}{*}{$\begin{array}{c}\text { Supplementary } \\
\text { Activities }\end{array}$} & \multirow{4}{*}{$\begin{array}{l}\text { Supplementary } \\
\text { Activities }\end{array}$} & \multirow{4}{*}{$\begin{array}{c}\text { Supplementary } \\
\text { Activities }\end{array}$} & \multirow{4}{*}{$\begin{array}{c}\text { Local Transportation \& } \\
\text { Warehousing }\end{array}$} & Local cargo collection \\
\hline & & & & & $\begin{array}{c}\text { Regional transportation (domestic, } \\
\text { truck) }\end{array}$ \\
\hline & & & & & Local freight delivery \\
\hline & & & & & Local Warehousing \\
\hline \multirow{5}{*}{ NA } & \multirow{5}{*}{$\begin{array}{c}\text { Main } \\
\text { Activities }\end{array}$} & \multirow{5}{*}{ NA } & \multirow{5}{*}{$\begin{array}{c}\text { Supplementary } \\
\text { Activities }\end{array}$} & \multirow{5}{*}{$\begin{array}{c}\text { Global Transportation \& } \\
\text { Warehousing }\end{array}$} & Global Local cargo collection \\
\hline & & & & & $\begin{array}{l}\text { International transportation } \\
\text { (multimodal) }\end{array}$ \\
\hline & & & & & Global Local freight delivery \\
\hline & & & & & Global Warehousing \\
\hline & & & & & Chartering \\
\hline \multirow{3}{*}{$\begin{array}{l}\text { Supplementary } \\
\text { Activities }\end{array}$} & \multirow{3}{*}{$\begin{array}{c}\text { Supplementary } \\
\text { Activities }\end{array}$} & \multirow{3}{*}{$\begin{array}{c}\text { Main } \\
\text { Activities }\end{array}$} & \multirow{3}{*}{$\begin{array}{c}\text { Main } \\
\text { Activities }\end{array}$} & \multirow{3}{*}{$\begin{array}{l}\text { Logistics Management } \\
\text { Services }\end{array}$} & Consulting service \\
\hline & & & & & $\begin{array}{l}\text { Transportation management (planning, } \\
\text { control, transportation, loading and } \\
\text { unloading) }\end{array}$ \\
\hline & & & & & IT service \\
\hline \multirow{3}{*}{ NA } & \multirow{3}{*}{ NA } & \multirow{3}{*}{$\begin{array}{c}\text { Main } \\
\text { Activities }\end{array}$} & \multirow{3}{*}{$\begin{array}{c}\text { Main } \\
\text { Activities }\end{array}$} & \multirow{3}{*}{$\begin{array}{l}\text { Customized Value- } \\
\text { Added Activities }\end{array}$} & Packaging and labeling \\
\hline & & & & & Manufacturing service \\
\hline & & & & & $\begin{array}{c}\text { Special transportation and loading and } \\
\text { unloading }\end{array}$ \\
\hline \multirow{3}{*}{ NA } & \multirow{3}{*}{ NA } & \multirow{3}{*}{$\begin{array}{l}\text { Main } \\
\text { Activities }\end{array}$} & \multirow{3}{*}{$\begin{array}{l}\text { Main } \\
\text { Activities }\end{array}$} & \multirow{3}{*}{$\begin{array}{l}\text { Customer Relationship } \\
\text { Management }\end{array}$} & Order processing \\
\hline & & & & & $\begin{array}{l}\text { Administrative support (billing, claim, } \\
\text { etc.) }\end{array}$ \\
\hline & & & & & On-demand service \\
\hline
\end{tabular}

\section{Impact of Digital Convergence Technology on the Value Chain of Logistics Companies}

\subsection{Examples of Digital Technology Application}

Digital convergence technology is attracting attention as an alternative to the difficulty of securing manpower in the logistics industry, and contributes to cost reduction through efficient logistics process. Digital convergence technology is used for logistics functions such as transportation, storage, inventory management, unloading, packaging, and information. Practical examples of optimizing transportation, reducing inventory, and shortening lead time by introducing digital convergence technology have been announced[23]. In this study, as shown in [Table 3], cases of digital convergence technology application by companies were investigated and analyzed. Research reports, articles, and Internet data published 
until recently were investigated and the applied cases of industries (logistics and shippers) were organized by technology and logistics value chain. It summarized the changes in logistics business and presented implications for the impact of the logistics enterprise value chain.

[Table 3] Practical Examples of Digital Convergence Technologies

\begin{tabular}{|c|c|c|}
\hline Digital Convergence & \multicolumn{2}{|c|}{ Practical Examples } \\
\hline $\begin{array}{l}\text { Autonomous Driving } \\
\text { Technology (Vehicles) }\end{array}$ & $\begin{array}{l}\cdot \text { Daimler-Benz (Daimler Freightliner } \\
\text { Inspiration) } \\
\cdot \text { Uber (Uber-Freight/Otto autonomous truck) } \\
\cdot \text { Google (Autonomous Delivery Platform) } \\
\cdot \text { Amazon (self-driving truck with Embark) }\end{array}$ & $\begin{array}{l}\cdot \text { FedEx (same-day unmanned delivery car Roxo) } \\
\cdot \text { UPS (self-driving trucks with two-simple) } \\
\cdot \text { USPS (self-driving trucks with two-simple) } \\
\cdot \text { DNV GL (autonomous vessel) }\end{array}$ \\
\hline Drones & $\begin{array}{l}\cdot \text { Amazon (Prime Air) } \\
\cdot \text { Amazon (Airborne Fulfillment Center) }\end{array}$ & $\begin{array}{l}\text { · Google (Wing Project) } \\
\text { · UPS (Drone Medicine Delivery Service) }\end{array}$ \\
\hline Robots & $\begin{array}{l}\cdot \text { Amazon (KIVA) } \\
\cdot \text { Amazon (Image recognition inventory } \\
\text { management robots) } \\
\cdot \text { Domino (DRU) } \\
\cdot \text { Wal-Mart (Stock image recognition Bosa Nova } \\
\text { Robots) }\end{array}$ & $\begin{array}{l}\cdot \text { Autostore (Warehouse robot) } \\
\cdot \text { Fetch Robotics (Warehouse product handling robots) } \\
\cdot \text { DHL (Locusbot, Effibot, Boxter, Sawyer) } \\
\cdot \text { Swiss Post Office (mail robot) }\end{array}$ \\
\hline $\begin{array}{l}\text { Artificial Intelligence and Big } \\
\text { Data }\end{array}$ & $\begin{array}{l}\cdot \text { Wal-Mart (Stock image recognition Bosa Nova } \\
\text { Robots) } \\
\cdot \text { Jet.com (customized supply chain optimization } \\
\text { service) } \\
\cdot \text { Mungori.com (voice picking voice recognition } \\
\text { technology) } \\
\cdot \text { Modelez (Oreo Cookie Customizing Delivery) } \\
\cdot \text { ZARA (Inventory Optimal Distribution } \\
\text { System) }\end{array}$ & $\begin{array}{l}\cdot \text { UPS (Network Planning Tools, ORION routing } \\
\text { optimization)) } \\
\cdot \text { DHL (Delivery truck route optimization) } \\
\cdot \text { Amazon (Anticipatory Shipping) } \\
\cdot \text { DHL (Resilience 360, Big data utilization) } \\
\cdot \text { Maersk (Ship sensor data analysis) }\end{array}$ \\
\hline Cloud & $\begin{array}{l}\cdot \text { Alibaba (Cainiao acquisition, delivery service) } \\
\cdot \text { Google (Express service) } \\
\cdot \text { Target (Grand Junction, Shipt acquisition, } \\
\text { same-day delivery) } \\
\text { · Wal-Mart (Parcel acquisition, delivery service) } \\
\cdot \text { Amazon (Flex Service) } \\
\cdot \text { Stuart (Caruff, Burger King, Pizza Hut last mile } \\
\text { delivery) } \\
\cdot \text { Coupang (agricultural products-frozen food } \\
\text { delivery service, rocket delivery) } \\
\text { - UPS (My Choice, Access Point) } \\
\text { - Cargomatic, uShip (cargo space sharing) } \\
\text { · Ford (Transportation as a Service) }\end{array}$ & $\begin{array}{l}\cdot \text { Drophub, Roadie (shared transportation) } \\
\cdot \text { Flexe (sharing warehouse space) } \\
\cdot \text { DHL (Myways) } \\
\cdot \text { Convoy (truck online arrangement) } \\
\cdot \text { Shunfeng (Global shipping service in collaboration } \\
\text { with Flexport) } \\
\cdot \text { CJ Logistics (Hello) } \\
\cdot \text { Samsung SDS (cello integrated supply chain } \\
\text { solution) } \\
\cdot \text { Volkswagen (Rio supply chain platform) } \\
\cdot \text { GE (Predix operating system service) }\end{array}$ \\
\hline Blockchain & $\begin{array}{l}\cdot \text { SK C\&C, Samsung SDS (Logistics } \\
\text { Blockchain Technology) } \\
\cdot \text { Maersk (Logistics Blockchain Technology) }\end{array}$ & · Wal-Mart (Management of pork history) \\
\hline IoT & $\begin{array}{l}\cdot \text { Amazon (Locker) } \\
\cdot \text { FedEx (Sense Aware) }\end{array}$ & · DHL (SemProM : Semantic Product Memory \\
\hline $\begin{array}{l}\text { Augmented Reality Technology } \\
\text { and 3D Printing }\end{array}$ & $\begin{array}{l}\text { DHL (Logistics center augmented reality } \\
\text { construction) }\end{array}$ & $\cdot \mathrm{GE}$ (3D printing) \\
\hline
\end{tabular}

\subsubsection{Autonomous Driving Technology (vehicles)}

Among the digital convergence technologies, the most innovative field of change is related to transportation, and autonomous driving technology (vehicle) projects that automatically drive without human driving are being carried out in various places. Autonomous driving technology reduces long- 
distance delivery time by $1 / 4$ through 24 -hour transportation, and can save fuel by programming for the best fuel economy[25]. Self-driving ships are also being developed to operate without a crew by attaching GPS, infrared cameras, and sensors.

\subsubsection{Drones}

Drones have emerged as a new mode of transport that will change delivery, but the safety and regulatory issues of flight are pushing them in a different direction than initially expected. Starting with Amazon's drone delivery, there is a growing trend in places where access is dangerous, remote delivery, and cold chain-based drug delivery[5].

\subsubsection{Robots}

One of the biggest problems facing the logistics industry is the availability of labor, and the rapid growth of the e-commerce market has introduced robots into the logistics centers to handle increased shipments and increased volumes. The introduction of Amazon's "KIVA" robot is showing results in reducing logistics center operation costs and efficiency of storage space[19]. The introduction of robots aims to become a logistics center without human intervention by grasping the exact location of the sensor-attached cargo in the distribution center, picking, and automatically performing the receipt and delivery. In addition, robots that can collaborate called Cobots are systems that enable collaboration in a workspace where humans and robots are shared. These robots can be seen as a suitable type for the logistics industry where mobility is important.

\subsubsection{Artificial Intelligence and Big Data}

The technology that is drawing attention along with the fourth industry is artificial intelligence, and it is a technology that realizes the existing human decision-making through computer programs[5]. Artificial intelligence technology is synergistic with various digital convergence technologies such as big data, IoT, and robots, and the demand for big data technology is also greatly increased through rapid production of unstructured data such as sensor information, SNS, and video as well as conventional structured data. Artificial intelligence is used for supply chain planning and operation through logistics demand forecasting, preventive maintenance of logistics facilities and equipment, and supply chain risk avoidance, while big data technology can be used for predictive delivery by collecting and analyzing data on customer behavior.

\subsubsection{Cloud}

Cloud technology refers to cloud computing as providing infrastructure, software, and platform services through the Internet (cloud)[34]. Cloud computing serves as a platform for providing basic services such as big data and artificial intelligence, and is expanding its service range to a marketplace platform that can connect consumers and suppliers. In the field of logistics, a number of startups that provide cloud-based services are emerging as new business types.

\subsubsection{Blockchain}

Blockchain is a technology that has a great ripple effect on the logistics area where transactions are possible without reliable arbitration. Blockchain is a P2P-based distributed ledger storage method that can provide security, reliability, and efficiency, and will play an important role in the future as an intermediary for complex contracts and document verification in the logistics field[28]. However, the blockchain technology is still in the empirical test stage, and it remains a part that needs research in the application of the logistics field. 


\subsubsection{Internet of Things}

The Internet of Things is a technology that makes it possible to create high-value-added services using information as everything is connected to the Internet. IoT is related to open platforms, network infrastructure, sensors and devices, and security technologies, and in the logistics field, it plays an important role in tracking products, securing visibility, and responding to abnormal situations. It is widely applied in collecting and resolving information in overall supply chain management.

\subsubsection{Augmented Reality Technology and 3D Printing}

Augmented Reality technology is a technology that superimposes a virtual object on a real image. It can guide a variety of information to a worker throughout the entire logistics business, and can provide convenience of work by integrating the worker's equipment or documents into Augmented Reality technology. The 3D printing technology has a very large impact on logistics and supply chain fields, and it can be an environment where there is no burden of inventory because it can be manufactured and used as needed in a nearby place instead of transporting the produced product. The development of 3D printing technology in the future may have a decisive influence on the changes in the future logistics area, but there will be limitations from the viewpoint of mass production.

\subsection{Application of Digital Convergence Technology and Impact of Logistics Company Value Chain}

There are various cases of applying digital convergence technology to the logistics process of companies, and as it is called the fourth industrial technology, a number of studies have been conducted that the digital convergence technology brings innovative changes to logistics and supply chain management[5][23][28]. In a study that analyzes the impact of the fourth industrial revolution technology on logistics performance, the impact of logistics technology on logistics functions was presented[2]. In a study on the logistics industry structural change and future prospects according to the advent of the logistics 4.0 era, the core logistics ten technologies were derived and an analysis on the utilization of the logistics activity area was performed[5]. McKinsey analyzed the level of customer demand for digitalization of the logistics industry (trucks, forwarding, sea freight, rail freight, air freight) using Google search engines operating in 15 countries in Europe such as Germany, France and the UK.[35]. However, these studies were conducted from a comprehensive perspective on the impact of the logistics industry or logistics function. Therefore, this study analyzes the impact of digital convergence technology from the perspective of the value chain of logistics companies, and intends to promote the study from the perspective of crises and opportunities for securing competitiveness of logistics companies based on the researched cases.

\subsubsection{Impact of New Physical Process Changes on the Value Chain of Logistics Companies}

Among the digital convergence technologies applied to the logistics process, the technologies that have caused changes in physical processes can provide a new type of value chain with autonomous driving technologies (vehicles), robots, drones, and 3D printing technologies. Robots provide productivity and time savings in warehouse management, loading and unloading, and packaging, and drones are enabling delivery to remote areas and other places where access is difficult. The $3 \mathrm{D}$ printing can bring speed and convenience in transportation and inventory management[2]. Analyzing the logistics value chain, local transport using small transport and global transport using large transport (trailer, ship, aircraft) are all operated by humans, but autonomous driving technology (vehicles), robots, and drones use computers from a distance. It operates and drives automatically through the sensor. The application of robots in warehouses will play the same role as in transport. This digital convergence technology brings significant reductions in logistics costs through automation, and thus poses a threat to the transport and warehouse operation value chains of existing logistics companies. In addition, 
companies other than logistics companies, e-commerce companies such as Amazon, or some manufacturers, can provide opportunities to expand their business areas by securing their own delivery services. It also gives transportation platform companies like Uber and automakers like Mercedes and Ford the opportunity to easily access the transportation business. In the case study of the application of digital convergence technology, logistics companies (FedEx, UPS, USPS) are testing autonomous driving technology, but companies from other industries such as Amazon, Google, Daimler Benz, and Uber are showing more interest and technological advantage in autonomous driving technology (vehicle). Similar examples are shown in drone and robot technology.

Although 3D printing technology does not seem to have a direct relationship with logistics companies, it is also an area where transportation of logistics may be made unnecessary because products are printed and procured immediately where needed. However, it can also be viewed as an opportunity for logistics companies to advance into new business areas.

Looking at the investigated application cases, autonomous driving technologies (vehicles), robots, drones, and 3D printing technologies accompanying new physical changes are likely to affect the transportation and storage of logistics companies, but autonomous driving technologies (vehicles) cases are limited to local transportation or delivery, and there is no case for expansion to the global transportation area, and it is expected that it will take a lot of time. Robots applied to warehouse operations are generally seen as being at the level of coexisting with humans through partial automation. Drones are also in the test stage and are limited to affect local transportation or delivery of logistics companies. However, in these cases of digital convergence technologies, companies in other industries are showing prominence rather than logistics companies. As technologies develop in the future, it is necessary to prepare for the possibility of replacing the value chain of logistics companies.

\subsubsection{The effect of Information Collection and Information Sharing between Organizations on the Value Chain of Logistics Companies}

Digital convergence technologies that enable the collection of logistics information and information sharing between organizations are the Internet of Things and blockchain technology based on distributed ledger. The IoT can be applied to warehouse management, transportation, and last-mile delivery services[17]. Warehouse management is applied to equipment operation and maintenance, facility safety, and energy management, while transportation is used for product monitoring, transportation control and maintenance, and safety and risk management. Last mile delivery can be used to optimize delivery routing through delivery status tracking. The application of IoT is an opportunity to provide new services for logistics companies' specialized transport management and delivery, such as providing differentiated services by monitoring cold chain products. However, the expansion of the product storage space to various storage spaces such as Amazon 'Locker' from the concept of using the product storage space as limited to the existing warehouse has emerged as a new challenge for logistics companies due to IoT technology.

Blockchain technology is expected to improve visibility of cargo information, simplify logistics tasks involving complex transaction documents, and replace centralized logistics platforms[36]. In the case of blockchain application, tracking management and history management of import and export shipping logistics are being used on a pilot basis, and commercialization requires technological development and legal and institutional maintenance. Blockchain technology can provide new logistics services by securing efficiency in international transportation and transportation management of logistics companies. Using the Internet of Things and blockchain technology, digital and real information can be connected, and ultimately the entire supply chain can be connected. By promoting digitalization of logistics, optimal data operation will be possible by promptly approving and settling transactions, tracking transaction history, and preventing forgery[28]. 


\subsubsection{The Effect of Smart Decision Support on the Value Chain of Logistics Companies}

Big data technology and artificial intelligence technology are used for smart decision making in logistics business. Big data technology converts and analyzes collected and shared data into meaningful information, and artificial intelligence technology is used for natural language processing, video and voice recognition, and proof of theory. Big data technology is used for transport and delivery management considering data on various factors such as regional characteristics, weather, and distance traveled, and for pre-stock forecasting, and can be used to capture new business opportunities through extensive data analysis generated from logistics sales and operations[22]. Artificial intelligence can be used to support delivery work through voice recognition, automated cargo inspection through video recognition, text recognition of documents, preventive maintenance of logistics facilities and equipment, avoid supply chain risk, improve logistics automation efficiency, and predict volume of goods[37]. Application examples of big data technology provide opportunities for logistics companies (DHL, UPS) to streamline existing value chains of logistics companies, such as optimizing their local delivery and avoiding risk in transportation. Maersk, the largest shipping company, is actively responding to discovery of new business by utilizing ship's sensor data. On the other hand, companies in other industries are using big data technology to improve inventory efficiency, such as predicting inventory and determining inventory levels by location. Big data technology will have new business opportunities in the efficiency of local delivery value chains of logistics companies or management of supply chain crises, but improved inventory management of shippers companies is expected to make it difficult for logistics companies to respond to services, and there can be a threat of entering the delivery or storage value chain in the future. In the case of application of artificial intelligence, companies in other industries rather than logistics companies are using voice recognition technology for warehouse operations or stock image recognition. Artificial intelligence technology is a technology that generates synergy by being used in conjunction with big data, Internet of Things, and robot technology. It can provide opportunities and threats to the entire value chain of logistics companies as an alternative to labor-intensive logistics and operation of supply chains based on logistics demand forecasting. In the case of artificial intelligence technology, the fact that there are fewer cases of logistics companies than other industrial companies means that it is necessary to prepare for the threat to the entire value chain of logistics companies as artificial intelligence technology develops in the future.

\subsubsection{The Effect of Human-machine Interaction Support on the Value Chain of Logistics Companies}

In order to communicate between humans and machines in logistics, Augmented Reality technology that converts device data to maintain context is required. Augmented Reality technology can be used mainly for storage, picking, packaging, loading, and delivery operations in distribution centers. In order to realize Augmented Reality, image display technology, virtual object screen position technology, and virtual object expression technology are required, and it must be developed in connection with context recognition, optimization, and simulation. As for the application of Augmented Reality technology, a logistics company (DHL) used Google Glass in a logistics center to increase work efficiency as it was used for picking jobs. Augmented Reality technology is expected to have an impact on warehouse operations in the value chain of logistics companies, and will provide new opportunities for logistics companies as technology advances, but will play a role in improving human labor productivity until the distribution center is replaced by robots.

\subsubsection{The impact of Information Sharing and Service Provision Platforms on the Value Chain of Logistics Companies}

Cloud computing is a technology for sharing fast and accurate information by providing IT-related assets or services through the Internet in logistics business and providing big data or artificial intelligence-based logistics services. Through the cloud, information can be shared, exchanged, and 
instructions can be given, and the overall supply chain efficiency can be improved by integrating, automating, rearranging, and analyzing the flow of information among supply chain members[38]. Cloud technology is being applied to various logistics service platforms. As a logistics service provider platform, there are a logistics marketplace platform (Convoy, CJ Logistics) that acts as an intermediary between shippers and logistics service companies, and a vehicle manufacturer's platform (Volkswagen, Ford) that provides remote vehicle management. A supplier platform that provides a variety of services and solutions can affect the value chain of any logistics company. Transportation will be controlled by the platform and transportation management or customer management will be replaced by the platform's data mining and transportation planning algorithms. The vehicle manufacturer platform will enable efficient operation management through vehicle operation tracking and will be able to replace the transport management work of logistics companies. The logistics service shipper platform includes a logistics company idle resource sharing marketplace (Cargomatic, uShip, Flexe) and a shared economy platform (Drophub, Roadie, DHL: Myway) between shippers. The development of the logistics sharing economy platform will affect the local delivery value chain of logistics companies, and will replace logistics management or customer management services with platform functions. As the cloud-based platform expands the participation of shippers and logistics companies through various logistics supply chain solution functions, a representative player will appear in the logistics industry as well as platform companies in other industries (Facebook, eBay, Amazon, etc.), replacing the value chain of existing logistics companies.

\subsection{Implication}

\subsubsection{Analysis Approach}

In order to analyze the impact of digital convergence technology on the value chain of logistics companies, the value chain of logistics companies was subdivided into business types, cases of digital convergence technology applied to logistics business were summarized, and the impact on the value chain was analyzed. Although the case of applying digital convergence technology to logistics business is partially and in its infancy, research reports, articles, and internet data published until recently were investigated to empirically review the impact on the value chain of logistics companies. As shown in [Table 4], there were 28 logistics companies and 60 companies in other industries. The current status of 174 cases in which 10 digital convergence technologies were used in the logistics value chain was analyzed and summarized ([Fig. 3], [Fig. 4], [Fig. 5]).

\subsubsection{Result \& Discussion}

As for the digital convergence technology applied in the case study, cloud technology was most often applied, and this was seen as a result of the emergence of logistics startups of various platform businesses and conversion to logistics marketplaces with the development of internet or mobile technology. Artificial intelligence, autonomous driving technologies (vehicles), robots, and big data were applied more to the logistics value chain than other technologies. On the other hand, augmented reality or blockchain technology has not yet been applied to the logistics value chain. This seemed to be related to technical and legal and institutional problems. In the logistics value chain, it was found that digital convergence technologies were widely used for local freight delivery, regional transportation, transportation management, on-demand services, and local warehousing. However, in the logistics area of the industry, digital convergence technologies have generally appeared less. This seemed to be due to its still infancy. 
[Table 4] Practical Examples Overview

\begin{tabular}{|c|c|c|c|c|c|c|c|c|c|c|c|}
\hline $\begin{array}{l}\text { Logistics Digital Convergency } \\
\text { Value Chain }\end{array}$ & $3 \mathrm{D}$ & loT & Drones & Robotics & Blockchain & Big data & $\begin{array}{l}\text { Artificial } \\
\text { Intelligence } \\
\text { (Al) }\end{array}$ & $\begin{array}{l}\text { Autonomous } \\
\text { driving } \\
\text { technology } \\
\text { (Vehicles) }\end{array}$ & $\begin{array}{l}\text { Augmented } \\
\text { Reality }\end{array}$ & Cloud & Sum \\
\hline Local cargo collection & 1 & & & 2 & & & & & & 3 & 6 \\
\hline $\begin{array}{l}\text { Regional transportation (domestic, } \\
\text { truck) }\end{array}$ & 1 & & & & & 1 & & 6 & & 11 & 19 \\
\hline Local freight delivery & 1 & 1 & 4 & 2 & & 1 & 5 & 7 & & 39 & 60 \\
\hline Local Warehousing & 1 & & & 4 & & & 3 & & 1 & 4 & 13 \\
\hline Global Local cargo collection & 1 & & & & & & & & & 1 & 2 \\
\hline $\begin{array}{l}\text { International transportation } \\
\text { (multimodal) }\end{array}$ & 1 & & & & 2 & 1 & & & & 3 & 7 \\
\hline Global Local freight delivery & 1 & & & & & & 2 & & & 2 & 5 \\
\hline Global Warehousing & 1 & & & 1 & & & 1 & & & 2 & 5 \\
\hline Chartering & & & & & & & & & & 1 & 1 \\
\hline Consulting service & & & & & & 1 & & & & 2 & 3 \\
\hline $\begin{array}{l}\text { Transportation management } \\
\text { (planning, control, transportation, } \\
\text { loading and unloading) }\end{array}$ & & 2 & & & 2 & 2 & 4 & & & 8 & 18 \\
\hline IT service & & & & & & 1 & 1 & & & 3 & 5 \\
\hline Packaging and labeling & & & & 1 & & & & & & 1 & 2 \\
\hline $\begin{array}{l}\text { Special transportation and loading } \\
\text { and unloading }\end{array}$ & & 2 & & & & 1 & & & & 1 & 4 \\
\hline $\begin{array}{l}\text { Administrative support (billing, claim, } \\
\text { etc.) }\end{array}$ & & & & & & & & & & 4 & 4 \\
\hline Order processing & & 1 & & & & 1 & & & & 4 & 6 \\
\hline On-demand service & & & 1 & & & & 1 & & & 12 & 14 \\
\hline Sum & 8 & 6 & 5 & 10 & 4 & 9 & 17 & 13 & 1 & 101 & 174 \\
\hline
\end{tabular}

The results of analyzing the application of digital convergence technology were affecting the logistics value chain in various aspects, but provided three main implications.

First, the field where digital convergence technology was applied to the logistics value chain was local transportation and delivery (see [Fig. 4]). This emerged as new technologies such as autonomous driving technology (vehicle), drones and robots. However, it was found that there were few logistics companies in this field (see [Fig. 5]). Rather, other industrial companies such as Uber, Google and Daimler Benz were leading. As these digital convergence technologies grow, it seems likely that the value chain of logistics companies focused on local transportation or delivery will lose competitiveness. From a similar point of view, the area of local warehousing services could be a threat to logistics companies.

Second, there was a change in the value chain related to logistics management that was a unique task of existing logistics companies. Digital convergence technologies have emerged in value chains such as transportation planning, control, transportation management, IT services, and ordering and payment. Various online logistics platforms such as on-demand delivery platform, logistics sharing platform, and logistics supply chain solution platform provided fast and simple logistics management services. At the same time, the interface between shippers and logistics companies has been expanded in the Internet and mobile environment. These logistics service related platforms have been replacing the logistics management service area of existing logistics companies and are making logistics companies a simple logistics operator.

Third, there were few cases of digital convergence technology application in the field of logistics value-added services. It was recognized as a value chain that was difficult for other industries to access. Packaging and labeling, special transport, and handling operations were a diverse and complex service area. Since it was still an area for humans to practice, digital convergence technology seemed to have limitations to be challenged. In this field, it seemed necessary for logistics companies to subdivide areas where human tasks and digital convergence technology should be applied to maintain continuous competitiveness and to systematize the field knowledge of logistics companies. 


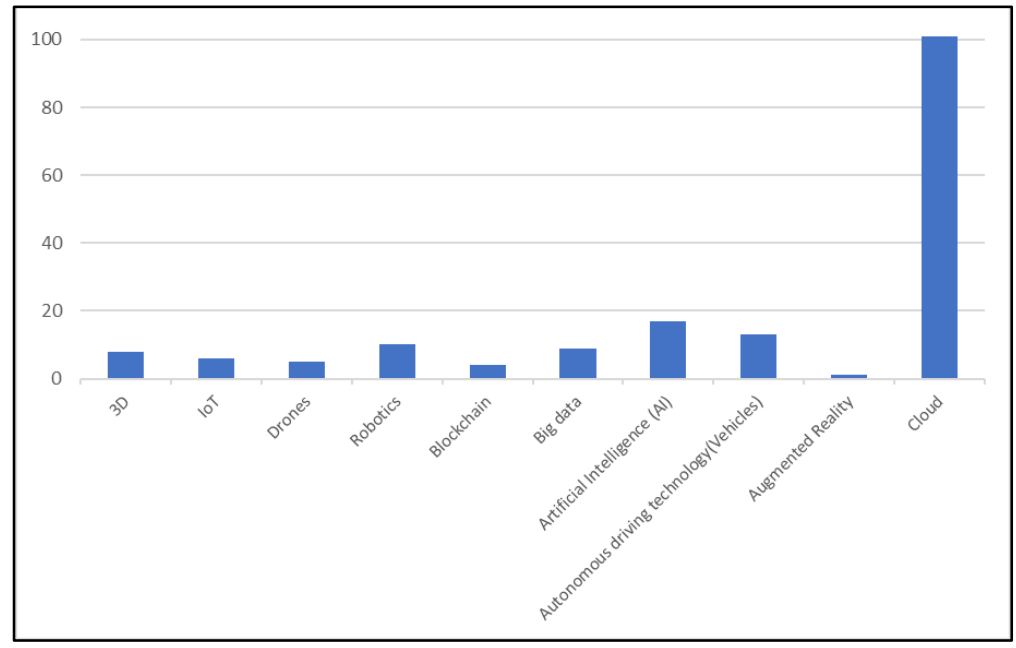

[Fig. 3] Digital Convergency Technologies Cases

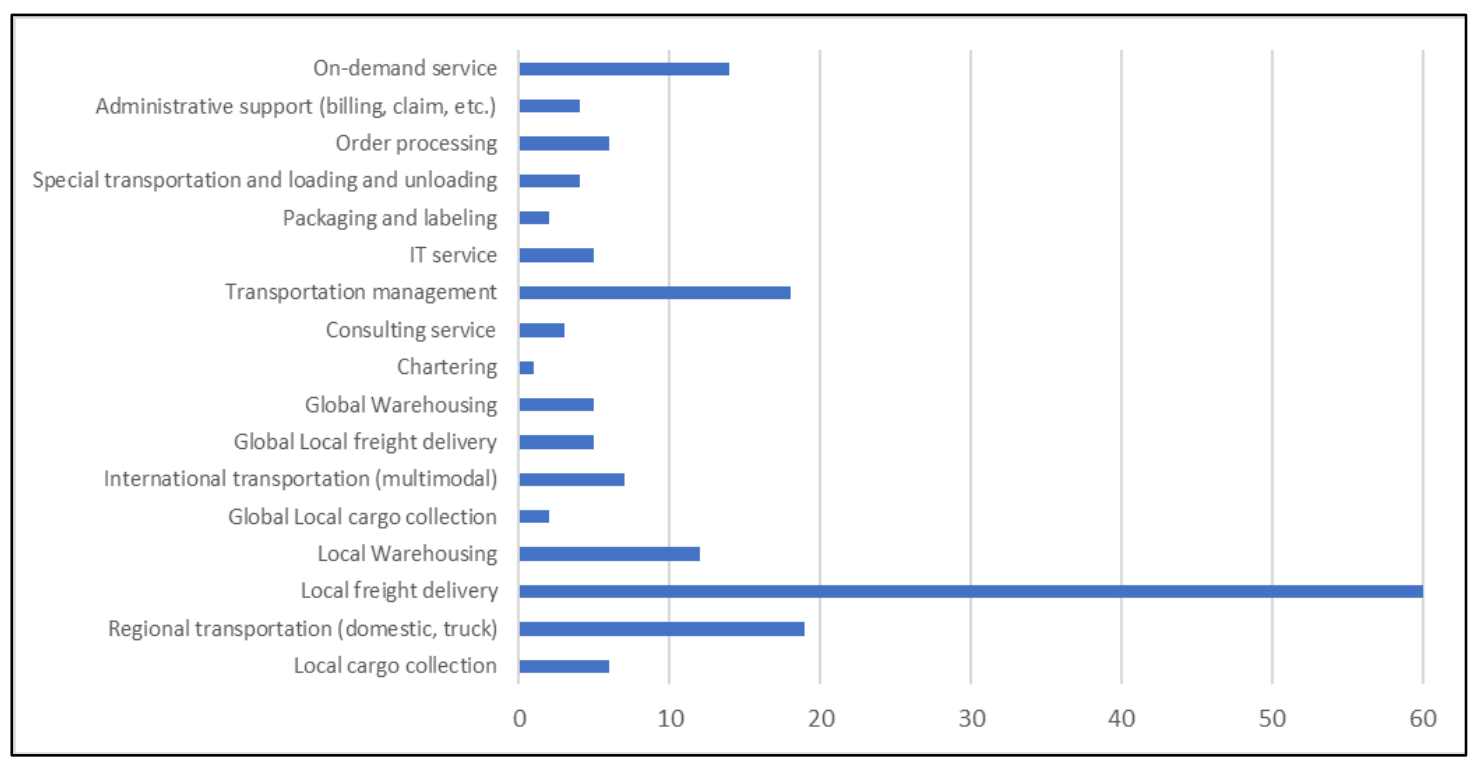

[Fig. 4] Digital Convergency Technologies Cases Applied to the Logistics Value Chain Area

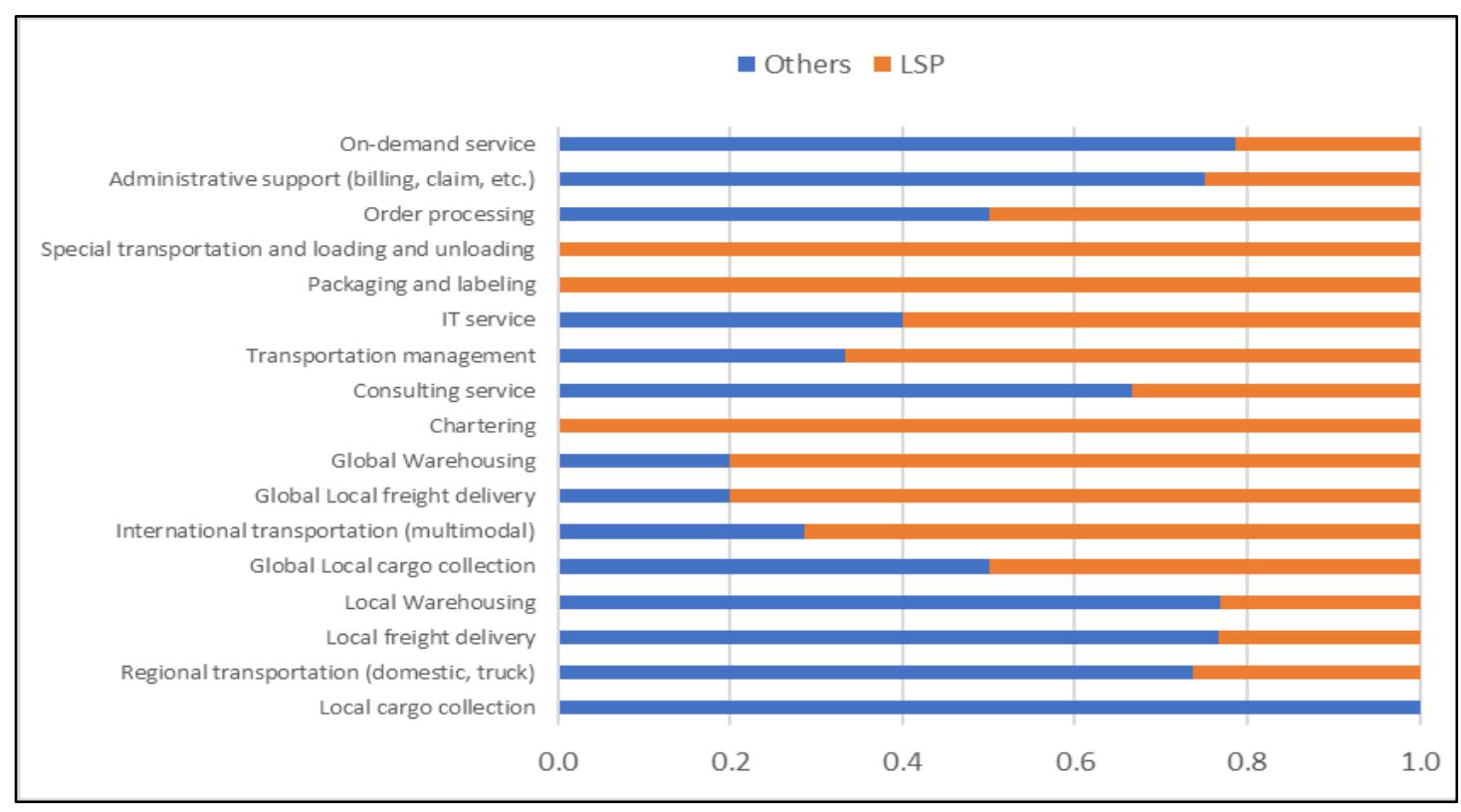

[Fig. 5] Digital Convergency Technologies Cases Ratio (LSP vs Others) 


\section{Conclusion}

The purpose of this study is to analyze the impact of the introduction of digital convergence technology on the existing logistics value chain and present future business directions for logistics companies in order to solve the difficulties in maintaining the sustainability and competitiveness of logistics companies with new technologies. Although the case where digital convergence technology is applied to the logistics field is in the early stages, the research cases were analyzed from the viewpoint of the logistics value chain to derive implications and present them. Existing logistics companies are likely to lose their competitiveness in many value chains due to the continuous development of digital convergence technology, and other industrial companies may replace them. Logistics companies also need continuous preparation for the development of digital convergence technology in response to changes, and countermeasures such as the introduction of digital convergence technology to secure customer experience of logistics companies, application of platform technology for horizontal cooperation, and construction of customized logistics service model in a cloud environment are required.

This study attempted to cope with future value chain changes by analyzing the effects of digital convergence technology on the logistics value chain. However, the application of digital convergence technology is also in its infancy. Since the impact on the value chain of logistics companies is not empirically considered, additional empirical analysis and continuous prediction of changes will be needed in the future. In the future research, application case analysis for each detailed digital convergence technology field or empirical analysis on the impact of the logistics company value chain is required, and it is necessary to study the relationship between the logistics company value chain and each platform by subdividing each platform type.

\section{Acknowledgments}

This work was supported by the 2020 academic research grant fund of Chungwoon University.

\section{References}

[1] Witkowski, K., Internet of Things, Big Data, Industry 4.0-Innovative Solutions in Logistics and Supply Chains Management, Procedia Engineering, (2017), Vol.182, pp.763-769.

[2] Choong-bae Lee, Jin-ho Noh, Jeong-hwan Kim, A Study on the Perception of the Impact of Fourth Industrial Revolution on the Performance of Logistics Management, Korea Logistics Review, (2017), Vol.27, No.5, pp.1-12.

[3] Kuihwa Park, A Study on the Digital Logistics Business Model Types in Logistics Startups, Korean Journal of Logistics, (2019), Vol.27, No.1, pp.15-33.

[4] Andra Angeleanu, New Technology Trends and Their Transformative Impact on Logistics and Supply Chain Processes, International Journal of Economic Practices and Theories, (2015), Vol.5, No.5, October, pp.413-419.

[5] Hyunjeong Nam, Eunhee Kim, Classification of Logistics Industry and Countermeasures in the 4th Industrial Revolution Era, The Korean Society of Management Consulting, (2018), Vol.18, No.3, pp.275-286.

[6] SangHwa Song, A Study on the Policy to Activate the Logistics Industry Using ICT, Korea International Trade Association, (2016)

[7] I. Harris, Y. Wang, H. Wang, ICT in multimodal transport and technological trends: Unleashing potential for the future, International Journal of Production Economics, (2014), Vol.159, No.1, pp.88-103.

[8] H. O. Nguyen, Critical factors in e-business adoption: Evidence from Australian transport and logistics companies, International Journal of Production Economics, (2013), Vol.146, pp.300-312. 
[9] Deutsche Post DHL Group, Logistics Trend Radar, Delivering Insight Today, Creating Value Tomorrow! version 2016, DHL Customer Solutions \& Innovation: Troisdorf, Germany, (2016)

[10] Delivering Change: The Transformation of Commercial Transport by 2025, McKinsey \& Company, (2016)

[11] Klaus Schwab, The Fourth Industrial Revolution, Crown Pub, (2017)

[12] Gartner, https://www.gartner.com/smarterwithgartner/gartner-top-10-strategic-technology-trends-for-2020/, Jul 09 (2020)

[13] DHL, LOGISTICS TREND RADAR, DHL Customer Solutions \& Innovation, (2016)

[14] Yeonjoo Min, Seungju Jeong, Soyoung Jang, Boosun Choi, Seungsub Yoon, Yongjin Kim, Yoonseok Chang, Logistics 4.0 Strategy and Policy for Emerging Business Model and Technology in Korea, The Korea Transport Institute, (2017)

[15] DHL, Logistics Trends Radar (Version 2018/19), (2018)

[16] Ben Gesing, Steve J. Peterson, Dirk Michelsen, DHL Trend Report Artificial Intelligence in Logistics, (2018)

[17] James Macaulay, Lauren Buckalew, Gina Chung, DHL Trend Report Internet of Thing in Logistics, (2015)

[18] https:// qz.com/709541/amazon-is-just-beginning-touse-robots-in-its-warehouses-and-theyre-already-making-a-huge -difference/, Jul 30 (2020)

[19] wycha, Analysis of Amazon's 4th Industrial Revolution, Digieco Issue\&Trend, (2017)

[20] Tom Bonkenburg, DHL Trend Report Robotics in Logistics, (2016)

[21] Denis Niezgoda, Stefan Endriß, DHL Trend Report Unmanned Aerial Vehicles in Logistics, (2014)

[22] Martin Jeske, Moritz Gruner, Frank Weiß, DHL Trend Report Big Data in Logistics, (2013)

[23] T. Schramm, S. Nogueira, D. Jones, Cloud Computing and Supply Chain: A Natural Fit for the Future, Logistics Management Magazine, (2011)

[24] Gina Chung, Denis Niezgoda, Rebecca Beissmann, Keya Chaturvedi, Timothy Kooi Jun Wen, DHL Trend Report 3D Printing and the Future of Supply Chains, (2016)

[25] http://www.greened.kr/news/articleView.html?idxno=29014, Jul 30 (2020)

[26] Katrin Zeiler, Denis Niezgoda, Gina Chung, DHL Trend Report Self-Driving Vehicles in Logistics, (2014)

[27] Holger Glockner, Kai Jannek, Johannes Mahn, Bjorn Theis, DHL Trend Report Augmented Reality in Logistics, (2014)

[28] Seon Hwa, Hyun Deok Kim, A Study on the Impacts of Block Chain Technology on the Logistics Industry, The e-Business Studies, (2019), Vol.20, No.3, pp.137-148

[29] Gina Chung, Bastian Gockel, Tuna Acar, Maximilian Forster, DHL Trend Report Blockchain in Logistics, (2016)

[30] E. Hofmann, K. Lampe, Financial statement analysis of logistics service providers: Ways of enhancing performance, International Journal of Physical Distribution \& Logistics Management, (2013), Vol.43, pp.321-342

[31] Eon-Seong Lee, An Analysis of North Korea's International Logistics Capability, Asia-pacific Journal of Convergent Research Interchange, (2020), Vol.6, No.9, pp.35-46.

[32] G. Prockl, A. Pflaum, H. Kotzab, 3PL factories or lernstatts? Value-creation models for 3PL service providers, International Journal of Physical Distribution \& Logistics Management, (2012), Vol.42, pp.544-561.

[33] E. Hofmann, F. Osterwalder, Third-Party Logistics Providers in the Digital Age: Towards a New Competitive Arena?, Logistics, (2017) Vol.1, No.2, p.9.

[34] Microsoft Azure, https://azure.microsoft.com/ko-kr/overview/what-is-cloud-computing/, Jul 30 (2020)

[35] https://www.mckinsey.com/industries/travel-transport-and-logistics/our-insights/travel-and-logistics-data-drives-therace-for-customers, Jul 30 (2020) 
Impact of Digital Convergence Technology on the Logistics Value Chain

[36]https://www.lotis.or.kr/tib03v.do?cn_id=2016061000001\&cn_type_cd=TIB\&menu_id=TIB00\&MENU_ID=TIB00\& searchKind $=\&$ searchWord $=\&$ currPage $=\&$ detailKind $=$, Jul $30(2020)$

[37] Wellers, Elliott, and Noga, 8 Ways Machine Learning Is Improving Companies' Work Processes, Harvard Business Review, (2017)

[38] A. T. Kearney, Digital Supply Chains: Increasingly Critical for Competitive Edge, European Excellence in Supply Chain Management, (2015) 